\title{
Grafen Kaplı Kimyasal Sensörlerin Şişme Davranışları ve Matematiksel Modelleme
}

\author{
Sibel ÇELİK AÇIKBAŞ ${ }^{1}$, Kemal BÜYÜKKABASAKAL ${ }^{2}$, Ali DENIZ ${ }^{3}$, Yaser \\ AÇIKBAŞ ${ }^{*}$, Rifat ÇAPAN ${ }^{5}$, Matem ERDOĞAN ${ }^{6}$ \\ *Sorumlu yazar: yaser.acikbas@ usak.edu.tr \\ ${ }^{1}$ Uşak Üniversitesi, Fen Fakültesi, Matematik Bölümü, UŞAK \\ Orcid No: 0000-0001-8684-1406 / e_sibel_celik@ @otmail.com \\ ${ }^{2}$ Uşak Üniversitesi, Mühendislik Fakültesi, Elektrik-Elektronik Mühendisliği Bölümü, UŞAK \\ Orcid No: 0000-0002-5803-6255 / kemal.buyukkabasakal@usak.edu.tr \\ ${ }^{3}$ Uşak Üniversitesi, Fen Fakültesi, Matematik Bölümü, UŞAK \\ Orcid No: 0000-0002-6514-2320 / ali.deniz@usak.edu.tr \\ ${ }^{4}$ Uşak Üniversitesi, Mühendislik Fakültesi, Malzeme Bilimi ve Nanoteknoloji Mühendisliği Bölümü, UŞAK \\ Orcid No: 0000-0003-3416-1083 / yaser.acikbas@usak.edu.tr \\ ${ }^{5}$ Balıkesir Üniversitesi, Fen Fakültesi, Fizik Bölümü, BALIKESİR \\ Orcid No: 0000-0003-3222-9056 / rcapan@gmail.com \\ ${ }^{6}$ Balıkesir Üniversitesi, Fen Fakültesi, Fizik Bölümü, BALIKESIR \\ Orcid No: 0000-0003-4440-1896 / matemer@gmail.com
}

\begin{abstract}
Öz: Bu çalışmada, grafen kaplı Langmuir-Blodgett (LB) ince filmlerin şişme davranışları Kuartz Kristal Mikrobalans (KKM) tekniği kullanılarak incelenmiştir. Bu filmler, bazı organik buharların (aseton, etanol ve metanol) difüzyon katsayı değerlerinin hesaplanması (Fick'in erken-zaman difüzyon kanunu kullanılarak) için oda sıcaklığında etkileşmeye bırakılmıştır. Difüzyon katsayı değerleri sırası ile aseton, etanol ve metanol için $20.43 \times 10^{-16}, 1.30 \times 10^{-16}$ ve $0.91 \times 10^{-16} \mathrm{~cm}^{2} \mathrm{~s}^{-1}$ olarak hesaplanmıştır. Benzer sıralama grafen kaplı KKM sensörünün tepkisi (frekans değişimi, $\Delta \mathrm{f})$ için de aseton $(342 \mathrm{~Hz})>$ etanol $(76 \mathrm{~Hz})>$ metanol $(51 \mathrm{~Hz})$ olarak elde edilmiştir.
\end{abstract}

Anahtar Kelimeler: Kuartz kristal mikrobalans, grafen, kimyasal sensör, matematiksel modelleme

\section{Mathematical Modelling and Swelling Behaviors of Graphene-coated Chemical Sensors}

\begin{abstract}
In this work, the swelling behaviors of the graphene-coated Langmuir-Blodgett (LB) thin films are investigated by using Quartz Crystal Microbalance (QCM) technique. These films were exposed to several Volatile Organic Compounds (VOCs) (acetone, ethanol and methanol) at room temperature to calculate diffusion coefficients of these organic vapors by using the early-time Fick's law of diffusion. The diffusion coefficients are calculated to be $20.43 \times 10^{-16}, 1.30 \times 10^{-16}$ and $0.91 \times 10^{-16} \mathrm{~cm}^{2} \mathrm{~s}^{-1}$ for acetone, ethanol and methanol, respectively. Similar ranking was obtained for the response of graphene-coated QCM sensor as a frequency shift $(\Delta \mathrm{f})$; acetone $(342 \mathrm{~Hz})>$ ethanol $(76 \mathrm{~Hz})>$ methanol $(51 \mathrm{~Hz})$.
\end{abstract}

Keywords: Quartz crystal microbalance, graphene, chemical sensor, mathematical modelling

\section{Giriş}

Grafen, iki bitişik karbon atomu arasında güçlü kovalent bağların oluştuğu sp2 karbon altıgen ağlardan oluşan fiziksel ve kristal yapısı bakımından büyük bir spesifik yüzey alanına, yüksek iç 
hareketliliğe ve mekaniksel esnekliğe sahip önemli bir malzemedir (Cai ve ark., 2015; Zhang ve ark., 2014). Büyük potansiyele sahip malzemeler olan grafenler, yakit hücreleri, nanokompozitler, fotovoltaik aletler, elektronik aletlerin üretimi ve sensörler vb. uygulamalarda önemli roller üstlenmesi sebebi ile bu alanda çalışmalar yapan araştırmacıların dikkatini çekmiştir (Zhu ve ark., 2013; Zhang ve ark., 2013; Liu ve ark., 2008; Seger ve Kamat, 2009). Grafen kullanılarak üretilen sensörler, yüksek iletkenlik, geniş yüzey alanı ve güçlü mekaniksel dayanıklılığa sahip olması sebebi ile literatürde özellikle kimyasal sensör çalışmalarında yer almaya devam etmektedir. Zhihua ve ark. (2012), kuartz kristal yüzey üzerine ince tabaka grafen kaplama işlemi gerçekleştirerek, formaldehit (HCHO)'in dedekte edilmesi için kimyasal sensör geliştirmişlerdir. Grafen kimyasal sensörü, farklı konsantrasyonlardaki HCHO gazına belli frekans değişimleri göstermiştir. Elde edilen yüksek lineer korelasyonlu deney sonucu ile, HCHO gazının dedekte edilmesinde, grafen modifiyeli Kuartz Kristal Mikrobalans (KKM) sensörünün büyük bir potansiyele sahip olabileceği ortaya çıkmıştır (Yao ve ark., 2011; Zhihua ve ark., 2012). Benzer bir çalışmada, Quang ve ark. (2014) tarafından oda sıcaklığında geliştirilen grafen kaplı KKM kimyasal sensörün bazı Uçucu Organik Bileşikler (UOB)'e hassasiyeti araştırılmıştır. Grafen kaplı KKM sensörü ile bu çalışmada kullanılan UOB arasında en yüksek hassasiyeti etanol gazına göstermiştir. UOB'nin dedekte edilmesinde en önemli işlem ince film sensörlerinin hazırlanmasıdır. İnce film üretiminde kullanılan metotlara dönel kaplama, kimyasal ya da fiziksel buhar yöntemi ile LangmuirBlodgett (LB) teknikleri örnek verilebilir. LB ince film üretme tekniği diğer tekniklere kıyasla, moleküler seviyede iyi istiflenmiş ve kalınlık kontrolü imkanı sağlayan ince filmlerin üretilmesine olanak sağlamaktadır (Capan ve ark., 2010). Bu teknik, yüksek seçiciliğe sahip kimyasal sensör cihazlarının geliştirilmesinde önemli roller üstlenen homojen ve çok tabakalı grafen LB ince filmlerin hazırlanmasını mümkün kılmaktadır (Botcha ve ark., 2014; Yao ve ark., 2014).

$\mathrm{Bu}$ çalışmada kuartz kristal yüzey üzerine çok tabakalı grafen ince filmleri LB ince film tekniği ile üretilmiştir. Grafen moleküllerinin kütle değişimlerine bağlı olarak şişme davranışları Fick'in difüzyon kanunu kullanılarak araştırılmıştır. Grafen kaplı KKM sensörünün şişme dinamiğinin aydınlatılabilmesi için ince film sensörü aseton, etanol ve metanol zararlı UOB'i ile doymuş konsantrasyonlarda etkileşmeye bırakılmış ve KKM sensörünün verdiği tepkiler (frekans değişimi) zamanın fonksiyonu olarak kaydedilmiştir. Zararlı UOB'nin grafen kaplı ince filmin içine difüzyonu ve şişme davranışlarının araştırılması için matematiksel modelleme 
Fick'in ikinci yasası kullanılarak geliştirilmiştir. Matematiksel modellemede, elde edilen deneysel KKM gaz kinetik sonuçları Fick'in difüzyon kanununa uyarlanarak UOB için difüzyon katsayısı $(D)$ hesaplanmıştır.

\section{Materyal ve Metot}

\subsection{Sensör Malzemesi}

İnce film üretiminde kullanılan grafen malzemesi Sigma Aldrich firmasından temin edilmiştir. Grafenin kimyasal yapısı Şekil 1 'de verilmiştir.

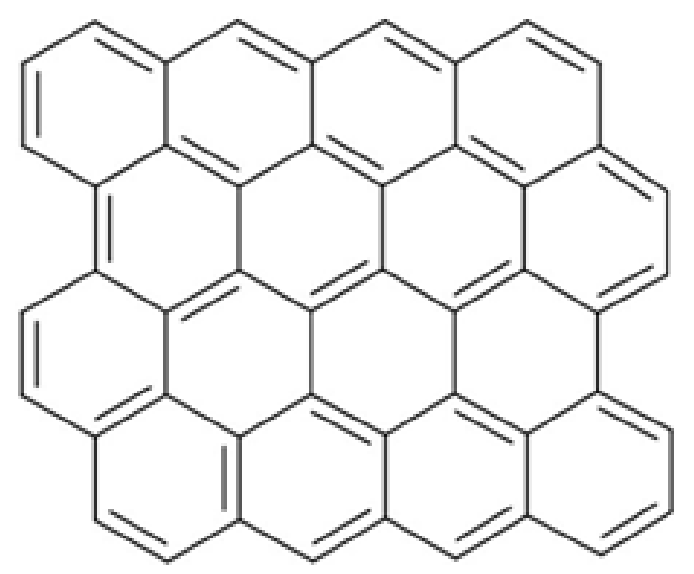

Şekil 1. Grafen'in kimyasal yapısı

\subsection{Kuartz Kristal Mikrobalans (KKM)}

KKM sisteminde metal elektrotlar, uygun bir elektronik devreye bağlandığında kuartzın piezoelektrik özelliğinden dolayı belirli bir frekans ile titreşir. Kuartz kristalleri karşıt piezoelekrik etkiyi ortaya koymaktadır. Uygulanan gerilim mekaniksel bir bozulma yaratır. Kuartzın bu özelliği KKM'deki az miktardaki kütle değişimlerini ortaya çıkarmaktadır. Kuartzın yüzeyi üzerindeki küçük bir kütle yükü kuartzın salınım frekansını küçültecektir. $\mathrm{Bu}$ frekanstaki değişim ile kütle miktarı arasındaki ilişki Sauerbrey eşitliği ile tanımlanmıştır (Sauerbrey, 1959). KKM sistemi çok küçük kütle değişimlerine hassas olması nedeniyle LB ince film tekniği ile üretilen filmlerin karakterizasyonunda tercih edilen önemli tekniklerdendir. Şekil 2'de elektronik devresi (şematik olarak) verilen Balıkesir Üniversitesi İnce Film Laboratuvarında geliştirilmiş olan KKM sistemi ile LB ince filmlerin üretilebilirliği ve homojenliği hakkında bilgi almak için kullanılacaktır. Ayrıca bu teknik yardımıyla, bu ince filmlerin UOB' e karşı olan hassasiyet testleri yapılabilmektedir.

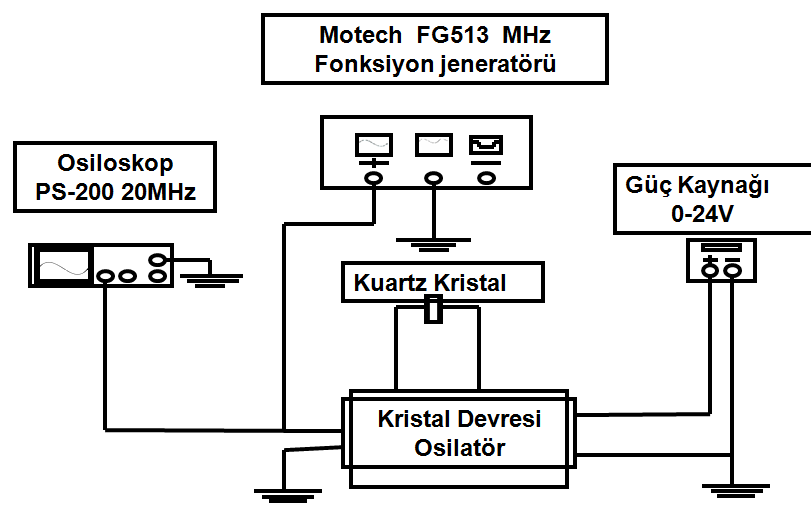

Şekil 2. Kuartz Kristal Mikrobalans sistemi şematik elektronik devre

Şekil 3'te ise KKM sistemi kullanılarak yapılması hedeflenen kinetik gaz sensör çalışma şeması verilmiştir. Ortama gaz ve hava verildiğinde gaz sensörünün gösterdiği tepki, frekans değişimine göre yorumlanmıştır. $\mathrm{Bu}$ yorumlar doğrultusunda 
gaz sensörünün göstereceği hızlı tepki, seçicilik, hassasiyetlik ve geri dönüşümlü tepki hakkında bazı bilgiler elde edilebilmektedir.

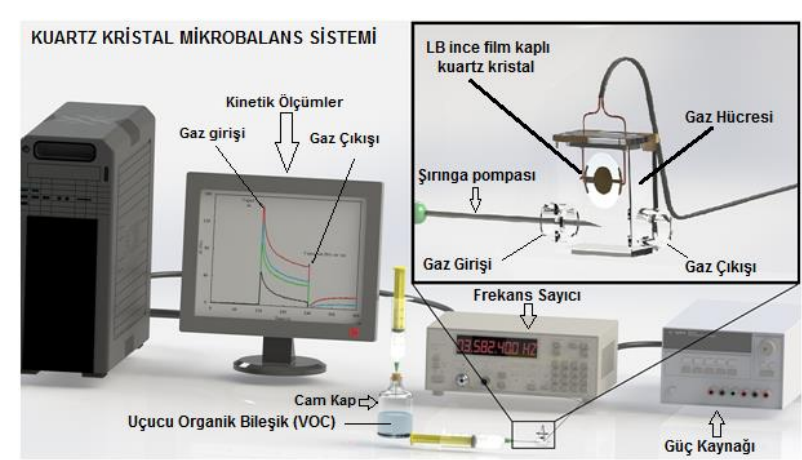

Şekil 3. KKM sistemi ile kinetik gaz sensörü çalışma şeması

\subsection{Fick' in İkinci Kanunu}

Fick'in birinci kanununa göre derişimin mesafe ile değişimi zamandan bağımsız iken, Fick'in 2. kanununa göre ise, derişim ve akı hem zaman, hem de mesafeye bağlıdır. Kısaca derişim ve akı, zaman ve mesafenin bir fonksiyonudur (Eşitlik 1).

$$
\frac{d C}{d t}=-\frac{d J}{d x}
$$

Eşitlik 1'in ikinci dereceden kısmi diferansiyeli alınarak,

$$
\frac{d J}{d x}=-D \frac{d^{2} C}{d x^{2}}
$$

elde edilir. Bu eşitlikte, - $\mathrm{dJ} / \mathrm{dx}$ ifadesi yerine $\mathrm{dC} / \mathrm{dt}$ ifadesi konduğunda, Fick'in 2. Kanunu olarak bilinen eşitlik elde edilir (Eş. 3) :

$$
-\frac{d C}{d t}=D \frac{d^{2} C}{d x^{2}}
$$

\section{Araştırma Sonuçları}

\subsection{Kuartz Kristal Mikrobalans (KKM) Ölçümleri}

Kuartz kristal yüzey üzerine 10 tabaka grafen LB ince film kaplanmış ve bu nano boyuttaki ince film sensörünün zararlı uçucu organik bileşikler ile etkileşmeleri incelenmiştir. Üretilen grafen LB ince film sensörünün aseton, etanol ve metanol organik buharlarıyla etkileşimi incelenip sensör maddesinin duyarlılığı hakkında bilgi edinilmiştir. Gaz molekülleri ince film tarafından tutulduğunda, ince film ile organik buharın etkileşmesi gerçekleşir. Ortama gönderilen gaz moleküllerinin derişimlerine göre LB ince filmlerin gazlarla olan tepkileri değişmektedir.

Grafen LB ince film sensörü, KKM' de gaz hücresine yerleştirildikten sonra ortam 0-120 saniye aralığında taze havaya maruz bırakılmıştır. Şekil 4'te 120 ile 240 s arasında ortama zararlı organik buharlar verilmiştir. Mikrolitrelik enjektör yardımıyla $0.5 \mathrm{ml}$ aseton buharı alınarak gaz hücresindeki film yüzeyine gönderilmiştir. Bu 120 saniyelik süreçte aseton buharı molekülleri ile grafen molekülleri etkileşmeye girdiğinden frekans değişiminde hızlı bir artış gözlenmiştir. 240. saniyede ortama tekrar hava gönderilmiş olup frekans değişiminin ilk haline döndüğü görülmüştür. $\mathrm{Bu}$ işlem etanol ve metanol zararlı organik buharları için de gerçekleştirilmiştir. 


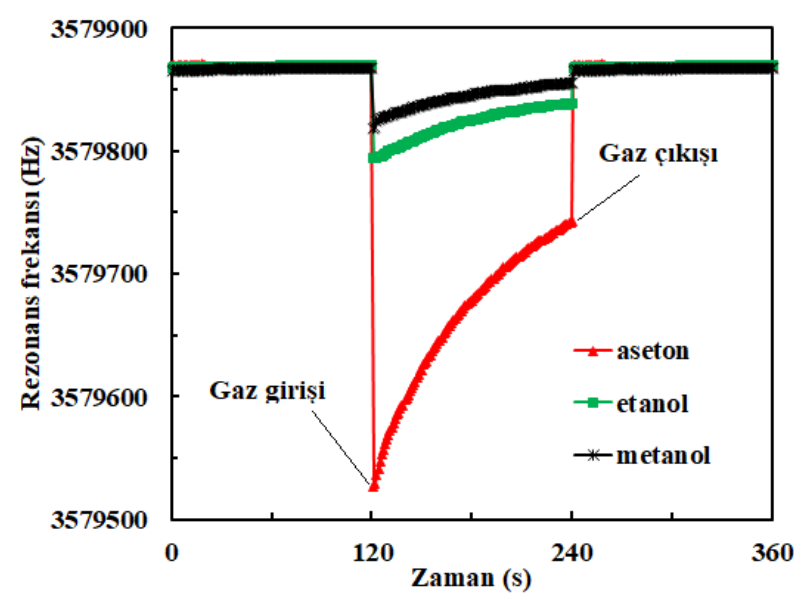

Şekil 4. Grafen LB ince film sensörünün zararlı UOB’ e karşı tepkisi.

Grafen LB ince filmlerin zararlı organik buhar ile olan etkileşimleri KKM sisteminde incelenmiştir. Grafen LB ince film sensörü-zararlı organik buhar etkileşmelerine ait grafikler yardımıyla difüzyon katsayıları hesaplanmıştır. Difüzyon katsayıları hesaplanırken Fick yasasından faydalanılmıştır.

Fick'in 2. yasası bir iki boyutlu düzleme uygulanırsa ve sabit difüzyon katsayısı kabul edilerek çözülürse, zamana bağlı konsantrasyon değişimi için (Crank, 1970);

$\frac{C}{C_{0}}=\frac{x}{a_{0}}+\frac{2}{\pi} \sum_{n=1}^{\infty} \frac{\cos n \pi}{n} \sin \frac{n \pi}{a_{0}} \exp \left(-\frac{D n^{2} \pi^{2}}{a_{0}^{2}} t\right)$

elde edilir. $\mathrm{Bu}$ eşitlikte, $a_{0}$ : kalınlık, $D$ : difüzyon katsayısı, $C, C_{o}, t$ ve $t=0$ zamandaki difüzyonun konsantrasyonunu, $x$ : $C$ 'nin ölçüldüğü mesafeyi gösterir.

$$
M=\int_{V} C d V
$$

Eşitlik (5), hacim elemanı için düşünülürse ve Eşitlik (4)'te yerine yazılırsa Eşitlik (6) elde edilir.

$$
\frac{M_{t}}{M_{\infty}}=1-\frac{8}{\pi^{2}} \sum_{n=0}^{\infty} \frac{1}{(2 n+1)^{2}} \exp \left(-\frac{(2 n+1)^{2} D \pi^{2}}{a_{0}{ }^{2}} t\right)
$$

Burada $M_{t}$ ve $M_{\infty}$, difüzyonun $t$ ve sonsuz zaman anındaki yüzeye difüz eden miktarlarıdır. Bu eşitlik daha basit bir forma indirgendiğinde Eşitlik (7) elde edilir.

$$
\frac{M_{t}}{M_{\infty}}=4 \sqrt{\frac{D}{\pi a_{0}^{2}}} t^{1 / 2}
$$

Erken zaman denkliği olarak adlandırılan bu eşitlik, difüzyon katsayısının hesaplanmasında kullanılır. KKM sisteminde alınan ölçümlerde grafen LB ince film sensörü ile organik buhar etkileşiminde, filmin içerisine difüz eden zararlı organik buhar moleküllerinin miktarı arttıkça $\Delta f$ frekans değişimi de arttığından Eşitlik (7), Eşitlik (8)'e dönüştürülebilir.

$$
\frac{M_{t}}{M_{\infty}} \cong \frac{\Delta f(t)}{\Delta f(\infty)}=4 \sqrt{\frac{D}{\pi d^{2}}} t^{1 / 2}
$$




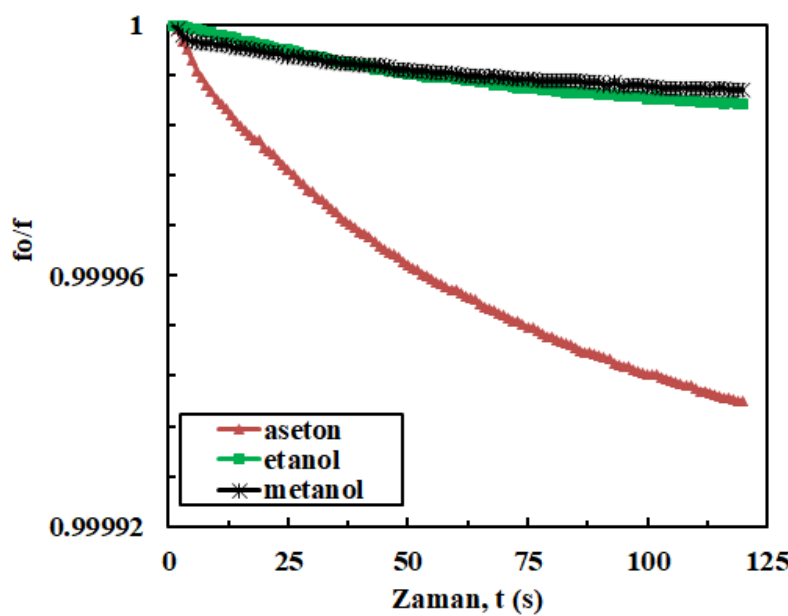

Şekil 5. Normalize frekans değişiminin zamana göre değişimi.

Şekil 5'ten elde edilen veriler kullanılarak

[ $\Delta f(t) / \Delta f(\infty)]$ 'un zamanın kareköküne karşı grafiği elde edilmiş (Şekil 6) ve bu grafiğin eğiminden grafen LB ince film sensörü için aseton, etanol ve metanol buharlarının doymuş konsantrayonlardaki difüzyon katsayıları Eşitlik (8) yardımıyla hesaplanmıştır.

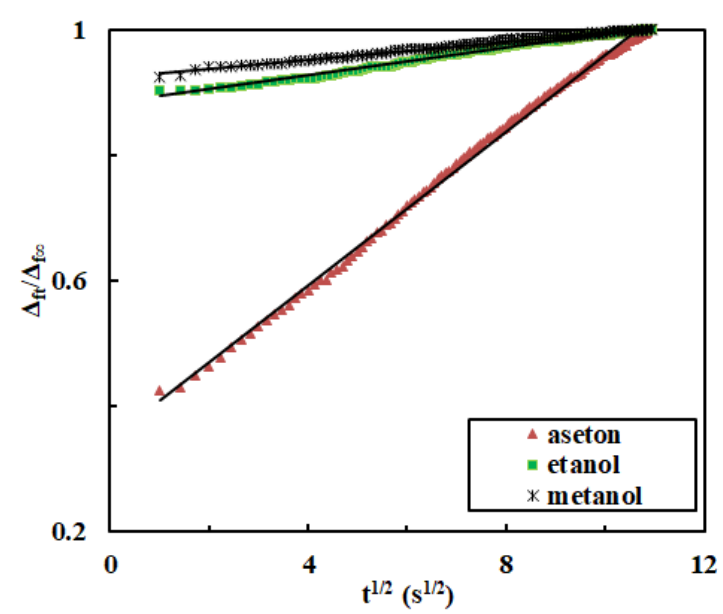

Şekil 6. Normalize frekans değişiminin zamana göre değişimi.

Tablo 1'de, grafen LB ince film sensörünün KKM'de alınan gaz sensör ölçümleri, aseton, etanol ve metanol için incelendiğinde; aseton buharının doymuş konsantrasyon değerindeki difüzyon katsayısı değeri, etanol ve metanol buharlarına göre daha fazla olduğu gözlenmiştir. Etkileşme sürecinde, aseton buharına ait moleküller ince film yüzey içerisine daha hızlı difüz olmuştur.

Tablo 1. UOB' in difüzyon katsayı değerleri ve sensör-zararlı buhar etkileşimi frekans değişim değerleri

\begin{tabular}{|l|c|c|}
\hline UOB & $\boldsymbol{\Delta f}(\mathbf{H z})$ & $\begin{array}{c}\text { Difüzyon katsayısı }(\boldsymbol{D}) \\
\left(\mathbf{c m}^{\mathbf{2}} \mathbf{~ s}^{-1}\right)\end{array}$ \\
\hline Aseton & 342 & $20.43 \times 10^{-16}$ \\
\hline Etanol & 76 & $1.30 \times 10^{-16}$ \\
\hline Metanol & 51 & $0.91 \times 10^{-16}$ \\
\hline
\end{tabular}

\section{Tartışma}

LB ince film tekniği kullanılarak üretilen grafen kaplı KKM kimyasal sensör; aseton, etanol ve metanol zararlı UOB'i ile etkileşmeye bırakılmış ve tüm deneysel çalışmalar oda sicaklığında gerçekleştirilmiştir. Kinetik gaz deneyleri kütle değişimine hassas Kuartz Kristal Mikorbalans tekniği ile gerçekleştirilmiş, tüm veriler zamanın fonksiyonu olarak kaydedilmiştir. Grafen kaplı KKM sensörü bu çalışma kapsamında kullanılan UOB (aseton, etanol ve metanol) arasından en çok asetona karşı duyarlılık göstermiştir. Tablo 1'de frekans değişimi $(\Delta \mathrm{f})$ ve difüzyon katsayı değerleri aseton $>$ etanol $>$ metanol şeklinde sıralanmıştır. Elde edilen sonuçlar UOB'nin bazı fiziksel özelliklerinden yararlanılarak açıklanabilir. Aseton (58.08 g 
mol $^{-1}$ ) buharının molekül ağırlığının etanol $\left(46.11 \mathrm{~g} \mathrm{~mol}^{-1}\right)$ ve metanol $\left(32.04 \mathrm{~g} \mathrm{~mol}^{-1}\right)$ buharlarının molekül ağırlıklarına göre daha büyük olması; aseton buharının diğer organik buharlara kıyasla grafen LB ince filmin içine daha kolay/daha hızlı difüz olmasına neden olabilmektedir. Kinetik sonuçların, zararlı UOB'in molekül ağırlıklarına göre yorumlanması daha öce gerçekleştirilen ve literatürde yer alan çalışmalarla uyum göstermektedir (Acikbas ve ark., 2011; Sun ve ark., 2010). Molekül ağırlığı daha büyük olan zararlı organik buhar daha fazla rezonans frekansı değişimine neden olmaktadır. Sonuç olarak, Fick'in difüzyon kanununun elde edilen deneysel verilere matematiksel modelleme ile uyarlanması sonucu zararlı UOB'in difüzyon katsayı değerleri hesaplanmış olup literatüre kazandırılması sağlanmıştır.

\section{Kaynaklar}

Acikbas Y, Capan R, Erdogan M, Yukruk F (2011). Thin film characterization and vapor sensing properties of a novel perylenediimide material. Sens Actuators, B: Chem 160: $65-71$.

Botcha VD, Narayanam PK, Singh G, Talwar SS, Srinivasa RS, Major SS (2014). Effect of substrate and subphase conditions on the surface morphology of graphene oxide sheets prepared by Langmuir-Blodgett technique. Colloids Surf A Physicochem Eng Asp 452: $65-72$.

Cai W, Jiang S, Xu S, Li Y, Liu J, Li C, Zheng L, Su L, Xu J (2015). Graphene saturable absorber for diode pumped $\mathrm{Yb}: \mathrm{Sc}_{2} \mathrm{SiO}_{5}$ mode-locked laser. Opt Laser Techno 65: 1-4.

Capan I, Tarımc1 C, Capan R (2010). Fabrication of Langmuir-Blodgett thin films of porphyrins and investigation on their gas sensing properties. Sens Actuators B: Chem 144: $126-130$.

Crank J (1970). The Mathematics of Diffusion. Oxford University Press, London.

Liu Q, Liu ZF, Zhang XY, Zhang N, Yang LY, Yin SG, Chen YS (2008). Organic photovoltaic cells based on an acceptor of soluble graphene. Appl Phys Lett 92: 223303.

Quang VV, Hung VN, Tuan LA, Phan VN, Huy TQ, Quy NV (2014). Graphene-coated quartz crystal microbalance for detection of volatile organic compounds at room temperature. Thin Solid Films 568: 6-12.

Sauerbrey G (1959). Verwendung von schwingquarzen zur wägung dünner schichten und zur microwägung. Z Phys 155: 206-222.

Seger B, Kamat PV (2009). Electrocatalytically active graphene-platinum nanocomposites. Role of 2-D Carbon Support in PEM Fuel Cells. J Phys Chem C 113: 7990-7995.

Sun P, Jiang Y, Xie G, Yu J, Du X, Hu J (2010). Synthesis and sensitive properties of poly(bistriethylphosphine)-platinum diethynylbenzene for organic vapor detection. $J$ Appl Polym Sci 116: 562-567. 
Yao Y, Chen X, Guo H, Wu Z (2011). Graphene oxide thin film coated quartz crystal microbalance for humidity detection. Appl Surf Sci 257: 7778-7782.

Yao Y, Chen X, Li X, Chen X, Li N (2014). Investigation of the stability of QCM humidity sensor using graphene oxide as sensing films. Sens Actuators B: Chem 191: 779-783.

Zhang H, Grüner G, Zhao Y (2013). Recent advancements of graphene in biomedicine. $J$ Mater Chem B 1: 2542-2567.

Zhang Y, Du L, Lei Y, Zhao H (2014). Construction of high-quality CdSe NB/graphene Schottky diodes for optoelectronic applications. Mater Lett 131: 288-291.

Zhihua Y, Liang Z, Kaixin S, Weiwei H (2012). Characterization of quartz crystal microbalance sensors coated with graphene films. Procedia Eng 29: 2448-2452.

Zhu Z, Su M, Ma L, Ma L, Liu D, Wang Z (2013). Preparation of graphene oxide-silver nanoparticle nanohybrids with highly antibacterial capability. Talanta 117: 449-455. 